\title{
Deslindes étnicos en la historia de Amazonas, Perú
}

\author{
Arturo Ruiz Estrada ${ }^{a}$
}

\begin{abstract}
Resumen
Este artículo intenta presentar las divisiones étnicas que ocurrieron en el departamento de Amazonas cuando se produjo la presencia inkaica en sus territorios. Por lo general, se utiliza el término Chachapoya para designarlos sin considerar las antiguas divisiones tradicionales, pero una revisión de varios textos sugiere la existencia no solo de un grupo humano, sino de varios grupos con sus propias denominaciones. Las más recientes investigaciones arqueológicas revelan también algunas diferencias culturales entre esos grupos, lo cual confirma le existencia de varias unidades sociales con sus propios signos de identidad. Aparecen así, los grupos Luya, Chachapoya, Chilcho, Orimona, Jibaro y otros menos conocidos aún.
\end{abstract}

Palabras clave: arqueología, etnias, Amazonas, Perú.

\section{Abstract \\ ETHNIC BOUNDARIES IN THE HISTORY OF AMAZONAS, PERU}

This analytical report identifies and describes pre-Inkaic ethnic divisions in the department of Amazonas, Peru. Usually, the term Chachapoyas is used to designate the regional population without consideration of prior traditional divisions. However, a review of various texts suggests the presence of not one, but of many named groups. The most recent archaeological investigations also reveal some cultural differences between those groups, which confirm the existence of various social units with their own markers of identity. Among these are the Luya, Chachapoya, Chilcho, Orimona, Jibaro and other lesser known groups.

Keywords: Archaeology, Ethnic, Amazonas, Peru.

\section{Introducción}

El reconocimiento de los diversos grupos sociales que poblaron el territorio de los Andes, se fue perfilando conforme avanzaron los estudios sobre las informaciones contenidas en las crónicas. Pero progresaron mucho más cuando se iniciaron los análisis de una serie de documentos administrativos que contienen declaraciones de los propios nativos, en sus alegatos para esclarecer los conflictos surgidos durante la colonia. Tales documentos históricos y las versiones ofrecidas, constituyen una fuente de evaluación y reflexión sobre la distribución de los grupos sociales, en sus relaciones políticas, sociales y culturales. Esta situación coadyuvó, unas veces, al buen entendimiento de los grupos que actuaron en los Andes, pero en otras, más bien, se oscureció la información sobre los verdaderos pobladores de áreas específicas del territorio andino, teniendo en cuenta, además, que los trabajos

\footnotetext{
a Instituto de Investigaciones Histórico Sociales, Universidad Nacional Mayor de San Marcos

Correo electrónico: aruizestrada406@yahoo.com
} 
científicos no pueden poner de lado el dato histórico De otro lado, la información arqueológica sobre Amazonas viene dando cuenta de varias diferencias en la producción cultural entre dichos grupos, lo cual necesita ser esclarecido, razón que motivó nuestra inquietud orientada a deslindarlos en vista de las evidencias aportadas por varios estudiosos sobre el tema de los chachapoya. Anhelamos entonces contribuir a su debate e insistir en retomar la discusión de paradigmas coloniales, muchas veces interesados en mostrar hechos ajenos a la realidad histórica.

Por esa razón, apelando a la información etnohistórica y arqueológica intentamos realizar un deslinde sobre la real configuración étnica que existió en el departamento de Amazonas, con la intención de incrementar el conocimiento de la realidad histórica de esa área geográfica. Al respecto, varios cronistas refirieron con frecuencia que allí vivían los chachapoya y otros pueblos o naciones a los cuales, sin embargo, no los señalan con sus propias denominaciones seguramente por desconocerlas.

Si bien se ha ofrecido referencias sobre la existencia de varios grupos humanos en Amazonas, siempre se los ha considerado como unificados en una sola entidad social, cultural y política denominada Chachapoya. Se continúa usando, sin un análisis crítico términos acuñados de tiempos coloniales para hacer aparecer a un solo grupo humano como el gestor de las realizaciones culturales ocurridas en el actual territorio peruano de Amazonas. Podemos mencionar que para el caso del territorio andino se ha determinado que en el valle del Mantaro no solo se generalizó el término huancas para todos sus ocupantes, sino que existieron dos agrupaciones humanas denominadas Xauxas y Huancas (Hurtado Ames 2013). De igual manera se ha esclarecido la distribución de los llamados grupos humanos Chancas como originarios de la zona de Andahuaylas y no de áreas vecinas (Bauer et al. 2013). Para el caso de Amazonas ya se ha indicado que se requiere una reevaluación de los llamados chachapoya (Nystrom 2004; Schjellerup 2005; Church y Von Hagen 2008).

\section{Etnia y cultura material}

La etnicidad y su relación con la arqueología fue motivo de discusiones desde las décadas iniciales del siglo XX y aunque fue vinculada con el fomento de nacionalismos basados en la superioridad racial, ha sido, sin embargo, revaluada como concepto para poder aproximarse a la identificación de etnias del pasado (Jones 2003). En la comprensión de dicha conceptualización intentamos acercarnos al deslinde de los grupos humanos que ocuparon el territorio peruano de Amazonas desde tiempos anteriores a la ocupación incaica. Para los propósitos del presente informe, consideramos como grupos étnicos a determinados indicadores arqueológicos y datos suministrados por la información histórica de tiempos coloniales, que indican la presencia de indicios materiales diferentes existentes en un determinado territorio y los escritos con etnónimos nativos registrados por los españoles en el siglo XVI. Ambos instrumentos posibilitan vislumbrar una ocupación humana plural en Amazonas en vista de existir diversas expresiones arqueológicas, como también información escrita referente a determinadas áreas geográficas. Un estudio acerca del problema de la etnicidad proporcionado por investigaciones etnográficas practicadas en tiempos contemporáneos, invita a la reflexión sobre la necesidad de analizar con mucho detenimiento la situación de las unidades étnicas, las cuales, no obstante poseer sus particularidades se mantuvieron interrelacionadas (Barth 1976). Estos aportes nos permiten entender que, si bien en Amazonas habitaron varias etnias, ello no significa que estuviesen aisladas, sino que debieron mantener vinculaciones de diversa índole, pero conservando al mismo tiempo su propia identidad. Pensamos que el hecho de que los incas llamaran a los pobladores de Amazonas como pertenecientes a un solo grupo humano denominado Chachapoya, distorsionó la realidad histórica de sus verdaderos pobladores, asunto que se mantuvo en tiempos coloniales cuando algunos cronistas continuaron usando dicha denominación. Además, la fundación española de una ciudad a la que nombraron como Chachapoyas consolidó dicha generalización en vista de haberse constituido como el eje del poder colonial y neocolonial. 


\section{Informaciones}

Para el propósito de la presente información, utilizamos datos proporcionados por la investigación histórica, arqueológica, genética y etnográfica con la finalidad de hacer comprensible la realidad étnica que aconteció en Amazonas. Datos que, pese a no ser aún completos, puesto que se requieren incrementar las investigaciones en varias áreas del territorio de Amazonas, vienen, sin embargo, aclarando el problema de su diversidad étnica.

\subsection{Información histórica}

Damos inicio a este apartado citando, a manera de ejemplo, que, por muchas décadas, se consideró a los chankas como pobladores de los territorios de Huancavelica, Ayacucho y Apurímac, cuando en realidad tales chancas fueron, en efecto, los habitantes de algunas áreas de la zona ayacuchana y apurimeña, pero no del área de Huancavelica, aun cuando grupos de mitimaes chanca fueron trasladados en tiempos incaicos a esta área. Es más, se ha informado, por ejemplo, que en la región de Vilcashuamán «hubo diversas sociedades, entre ellas la chanca» (Santillana 2002: 556). No había pues, un solo grupo humano, sino varios. Es decir, la tradicional generalización no puede ser aceptada sin una discusión sustentada en los datos que traen los cronistas e investigadores contemporáneos. Por ello, el estudio o nuevo examen realizado por Julián I. Santillana con respecto al caso de los Chancas es ilustrador de las muchas alteraciones de la historia nativa. De igual manera, los estudios realizados por Brian Bauer en la sierra sur central aclaran que en los territorios de Apurímac y Ayacucho hubo varias poblaciones que no solo eran precisamente chancas, sino otras como la de los soras y lucanas, por ejemplo. Los Chancas tuvieron un territorio definido y circunscrito a la región de Andahuaylas de donde ellos eran originarios (Bauer et al. 2013).

Igualmente, una situación similar ocurre para el caso del territorio amazonense, para el cual todavía se viene considerando que el grupo humano que habitó sus tierras fue solo el de los chachapoya, pese a que, en realidad, hubo varios agrupamientos o curacazgos bien consolidados con nombre y territorio propio, e incluso todos de la misma categoría social, política y económica. Si bien muchos investigadores, siguiendo al cronista Inca Garcilaso de la Vega, sindican a los habitantes prehispánicos de Amazonas como Chachapoya: «La versión de Garcilaso es no obstante ampliamente aceptada, tanto por académicos como por estudiantes, como el área cultural Chachapoya arqueológica y etnohistórica» (von Hagen 2002a: 31). Debemos tener en cuenta que muchos aspectos de la obra de Garcilaso fueron cuestionados por confusos en varios hechos de la historia antigua, como lo ha comentado Idilio Santillana sobre la base de las críticas de varios estudiosos, que Garcilaso había usado datos de segunda y tercera mano, y que su obra fue señalada como infundada, inventada, mal informada, e incluso distorsionó algunos hechos históricos (Santillana 2002: 555).

En la misma línea de opinión, pero referente al conocimiento de los chachapoya, Adriana von Hagen nos advierte que Garcilaso, Cieza y Calancha: «curiosamente, ninguno de estos tres hombres visitó Chachapoyas; Garcilaso basó su narración en la desaparecida crónica de Blas Valera, Cieza recopiló su descripción de un informante desconocido, y Calancha basó sus escritos en las narraciones de un fraile agustino anónimo que fuera llamado a Chachapoyas por los primeros habitantes españoles, para la conquista de almas» (von Hagen 2002b: 25-27). De igual manera, la historiadora María Rostworowski afirma, con relación a la obra de Garcilaso su falta de veracidad en muchos aspectos de la sociedad inca pues «Los Comentarios reales no resisten un análisis, es imposible que historia alguna se desarrolle de un modo tan perfecto» (Rostworowski 2005: 83).

En efecto, comprendemos que las citas anotadas nos aclaran que debemos tomar con prudencia los escritos de Garcilaso sobre los chachapoya, pues él no estuvo en la región de Amazonas y lo que dijo fue también solo de oídas. Y si confundió, inventó, distorsionó y estuvo mal informado para casos tan cercanos a él, como lo fueron los incas y los chancas, con mayor razón no podemos confiar totalmente en sus afirmaciones sobre la realidad de Chachapoyas, área donde, vistas las cosas con más detenimiento, se descubre una historia mucho más compleja. Es interesante también 
mencionar lo afirmado por el cronista Sarmiento de Gamboa quien mencionó que el Inca Huayna Capac no solo conquistó a los chachapoya sino a otras tierras y naciones próximas (Sarmiento 1988: 140). Como se observa, este cronista menciona que existían cerca de Chachapoyas "ciertas tierras que podría conquistar" y que "llegó a los Chachapoyas y las otras naciones sus comarcanas". (Sarmiento 1988: 140; el subrayado es nuestro). Entre esas otras "naciones» debió figurar justamente los luya y chillao como llamaron los españoles a las poblaciones que ocupaban las actuales provincias de Luya y Utcubamba, principalmente. Pero también los chilchos y aquellas otras citadas por Waldemar Espinoza en su mapa publicado el año 1967.

Esta situación se grafica en dicho mapa donde se indica la distribución de los grupos étnicos del área Jatun Mayo (Marañón), Utcubamba y Huayabamba (Espinoza Soriano 1967) (Fig.1.7). De igual manera lo hizo la arqueóloga Inge Schjellerup, cuando ilustró un mapa tentativo de la distribución temprana del grupo étnico Chachapoya, que señala con un área punteada, dejando en blanco el espacio de la parte norte comprendida entre la desembocadura del río Utcubamba en el Marañón, y la margen derecha de este mismo río (Schjellerup 2005: 41); lo cual, según nuestra opinión, era el territorio Chillao. Anotamos también que ya se viene considerando la presencia de esos grupos según lo comenta Anna Guengerich (2014a: 62).

Desde luego que las divisiones señaladas vienen a ser una aproximación al entendimiento de la realidad existente antes de la llegada de los incas y españoles, porque ya desde tiempos de los incas las comunidades amazonenses habían sido alteradas en su distribución étnica en la medida que los gobernantes cusqueños las reorganizaron en relación a su propia estrategia geopolítica. A ello se añadió la alteración de las unidades étnicas amazonenses por parte de los españoles quienes crearon nuevas divisiones o agrupamientos, conforme, también, a sus particulares intereses políticos y económicos. Pues cuando estos se instalaron en los territorios de Amazonas, crearon corregimientos, pero manteniendo los mismos nombres que esas unidades territoriales poseían en tiempos antiguos. Debemos tener en cuenta esa realidad para profundizar aún más las investigaciones arqueológicas y etnohistóricas a fin de precisar, con mejores datos, los verdaderos linderos de los llamados curacazgos antiguos. Teniendo en cuenta, además, como lo afirma el historiador Lorenzo Huertas, que tales alteraciones sociales (Huertas Vallejos, 1998), tuvieron fuertes efectos que alteraron la original demarcación de los territorios nativos. De todas maneras, sólo señalamos en esta ocasión, a las etnias más conocidas hasta el momento, en nuestro afán de aportar algunos datos más a las investigaciones hechas por otros autores, como es el caso de las contribuciones de Waldemar Espinosa, Inge Schjellerup, Warren Church y otros. Asumimos también, que los datos de tiempos coloniales apoyan la identificación de los antiguos grupos humanos que poblaron un determinado territorio del Antiguo Perú como lo afirma un comentario transcrito por Inge Schjellerup (Schjellerup 2005: 55).

Keith Muscutt, en el libro Warriors of the Clouds, ha sugerido que de acuerdo a la distribución de los asentamientos entre los denominados chachapoya, no hubo un estado monolítico, sino una organización de clanes o aylllus independientes: «La escala, la distribución y la defensibilidad de los asentamientos chachapoya sugieren que eran entidades políticas relativamente independientes una confederación de ayllus enlazados por alianzas variables y conflictos internos, en vez de un estado monolítico y permanente» (Muscutt 1998: 28; la traducción es nuestra). Con respecto a un antiguo grupo mencionado por Waldemar Espinoza, Inge Schjellerup opina que: «Los pacllas fueron probablemente un grupo independiente conquistado después e incorporado al Tahuantinsuyo durante la época de Huascar» (Schjellerup 2005: 54).

\subsection{Información arqueológica}

Además de los datos que han proporcionado las fuentes escritas, es indispensable apelar al aporte de la investigación arqueológica, toda vez que esta sustenta también diferencias en la producción material, como indicadores de la existencia de varios grupos humanos con sus propias expresiones culturales. 
Algunas representaciones simbólicas que aparecen la arquitectura adquirieron predominancia en unos y no en otros. Al respecto, resulta bien clara la diferenciación simbólica que ostentaban, pues se afirmó en forma terminante que «los inmediatos de Leimebamba constituyen un límite entre una zona norteña de difusión de los símbolos del zigzag y de rombo, y de un área sureña, donde el simbolismo se reduce a la greca y el zigzag» (Lerche 1995: 51). De igual manera se ha reiterado que: «en la región norte de Chachapoyas predomina la ornamentación de triángulos y rombos; en la zona sur, los meandros» (Schjellerup 2005: 448).

Por su parte, algunos arqueólogos que han trabajado en la región de Amazonas piensan que aquí hubo, efectivamente, una agrupación de unidades sociopolíticas autónomas, a las cuales las tipifican como jefaturas (Schjellerup 1991: 315) o según interpretaciones actuales, como curacazgos en términos andinos (Church 2006: 476). En otras palabras, en dicha región, no habría existido un estado unificado ni reino preincaico, tal como ya lo expresara el historiador Waldemar Espinoza Soriano hace varios ańos (1967: 235). Incluso, como lo afirma Warren Church, existen variaciones regionales en la arquitectura, la cerámica y la iconografía por cuanto, en términos de diseño y detalles constructivos, no hay dos sitios Chachapoya idénticos (Church 2006:470). Aquí, el autor utiliza el término Chachapoya refiriéndose en forma general a los grupos arquitectónicos distribuidos en la cuenca del río Utcubamba.

Indudablemente se requieren mayores investigaciones en Amazonas, pero es ostensible la referencia a varios grupos humanos con sus propias diferencias, que se revelan en las expresiones alfareras y los patrones funerarios. Se ha afirmado con respecto al territorio generalizado como Chachapoyas, que allí alternaron diferentes tradiciones culturales visibles en sus tradiciones funerarias y alfareras (Koschmieder 2012: 11). Este autor al citar «Chachapoya» incluye a los territorios de la actual provincia de Luya y de Chachapoyas. La alfarería que él identificó en la provincia de Luya tiene, en términos generales, muchas afinidades con la de Kuélap antes que con las muestras informadas de la parte sur de la ciudad de Chachapoyas por Inge Schjellerup en la zona de Chuquibamba (Schjellerup 2005).

\subsection{Información genética}

Entre varios estudios publicados por Kenneth Nystrom sobre los chachapoya, en cuanto a las prácticas trepanatorias, mortuorias y diferencias genéticas, figura uno justamente referido a la investigación de restos óseos de tres sitios a lo largo de la cuenca del río Utcubamba. Tales sitios son uno al Norte en Kuélap, como también de las lagunas de Huayabamba y de Los Cóndores, al sur. Deduce de tales muestras que existen diferencias genéticas entre ellas, pues los restos óseos de Kuélap recibieron menos influencia genética externa. Creemos importante señalar estos datos, pese a que, como el mismo autor lo menciona, no basta solo los estudios biológicos para considerar diferencias étnicas si no que se los debe estudiar tomando en cuenta una perspectiva amplia de la investigación antropológica (Nystrom 2006).

\section{Grupos humanos en Amazonas}

Veamos entonces cuales fueron esos grupos humanos de Amazonas los cuales ejercieron su señorío en tiempos prehispánicos y subsistieron hasta la época colonial, de cuya existencia han quedado informes registrados cuando aparecieron los primeros documentos escritos.

\subsection{Chachapoya}

Fue el grupo más conocido por los incas y los españoles, quienes los identificaron con el término de Chacha o Chachapoyas incluyendo a casi todos los grupos del Nororiente peruano. Pero en realidad, su territorio abarcó, posiblemente, parte de la actual provincia de Chachapoyas, tal vez desde la zona de Levanto hasta la zona de Cajamarquilla en la sierra de la región de La Libertad, aunque 
existen datos que afirman que el territorio de los Luya se introducía en los espacios geográficos de Levanto hasta casi cerca de Cajamarquilla. Por eso, cuando los españoles fundaron la ciudad de Chachapoyas lo hicieron en el pueblo de la Jalca, zona que posiblemente se consideró como frontera con los grupos humanos del Norte. Los restos arqueológicos que nos legaron se distribuyen por la margen derecha del río Utcubamba, hasta el curso superior de los ríos que fluyen al Huayabamba. De ellos dieron referencia sus propias gentes cuando llegaron los españoles a sus territorios. Con esa información estos generalizaron dicho nombre para referirse a todos los habitantes de las nuevas tierras conquistadas de Amazonas. Sin embargo, con las nuevas informaciones, tanto documentales como arqueológicas, sabemos ahora que el territorio amazonense albergó a otros grupos humanos, muchos de ellos del mismo nivel social y político. Ciertos cronistas hispanos, quienes no visitaron la región, hablaron en términos genéricos sobre los chachapoya (Cieza 1962; Garcilaso 1967). Pensamos que por esta razón se ha expresado que «Los únicos autores que visitaron el área durante el período de la conquista fueron el padre Blas Valera y Vásquez de Espinosa. Todos los otros cronistas obtuvieron su información de segunda mano» (Schjellerup 2005: 93). Esos otros cronistas como Cieza y Garcilaso, de haber recorrido la región de Amazonas, seguramente habrían tenido que confrontar la verdadera realidad étnica regional y necesariamente ellos nos hubieran trasmitido un cuadro más completo de los diversos grupos humanos que aún vivían en el siglo XVI, y la verdadera ubicación de los chachapoya. Aspecto que sí fue abordado por quienes llegaron a la cuenca vecina del Chinchipe, donde encontraron que allí alternaban varios grupos con sus respectivos territorios e idiomas, como patagones de lengua caribe, chirinos de lengua candoshi, xorocas y tabancales de lengua palta jíbaro, copallines y baguas con su propio idioma, y los de sacata de lengua arahuaca (Torero 1993).

La palabra Chachapoyas fue un término aplicado al sitio donde los españoles se asentaron por tercera vez, dándole a la ciudad este mismo nombre, al pie del cerro Pumaurco y en terrenos que los huancas poseían desde el momento en que el estado incaico los instaló en dicho lugar. Ocuparon, también, casi en el mismo sitio denominado Luya-urco, término este que significa "cerro de Luya», porque tal vez eran dominios de los luyanos antiguos. Los españoles avanzaron desde el sur de la actual región de Amazonas en su incursión inicial hacia la parte norte, que era la zona donde se encontraban los luya y chillao. Era pues, la actual ciudad de Chachapoyas un punto norteño extremo y alejado del área de los territorios de los chachapoyanos prehispánicos, que posiblemente ocupaban solo la parte sur de Amazonas. De ahí que algunos arqueólogos, por razones de estudio, se refieran a la tradición Chachapoya, en vista de existir algunas expresiones culturales similares en los varios grupos sociales o curacazgos que poblaron lo que hoy es la región peruana de Amazonas. Entre esos estudiosos tenemos la opinión del arqueólogo francés Olivier Fabre, quien ha explicado que el nombre "Chachapoya» fue un término genérico dado a una provincia por los incas, que incluía otras pequeñas con fines administrativos (Fabre 2006: 71). Está claro, entonces, la división étnica existente y la necesidad de considerar a los restos arqueológicos como pertenecientes a cada uno de esas pequeñas provincias del Período Intermedio Tardío y, a nuestro parecer, no podría involucrárselos bajo un solo término.

Es interesante anotar que durante los conflictos judiciales entre cuatro líderes indígenas por el gobierno de los curacazgos de Leimebamba y Cochabamba, cuyas propias declaraciones figuran en la transcripción de nueve documentos referentes al litigio (Espinoza Soriano 1967), no se cita a ningún ayllu o curacazgo Chachapoya, ni aparece ningún testigo indígena que dijese ser de un pueblo, ayllu o territorio Chachapoya. Más bien, en las declaraciones que hicieron, mencionan a sus lugares de procedencia como indios de Leimebamba, Cochabamba, Chilcho, Cajamarquilla, la Jalca, por ejemplo, pero nadie declara ser de Chachapoya. Solo refieren a un distrito o provincia de Chachapoyas porque durante el tiempo de los conflictos antes mencionados, ya existía el enclave hispano al cual lo bautizaron como Chachapoyas. Igual situación observamos en los documentos transcritos, como Apéndice 14 por la arqueóloga Inge Schjellerup (Schjellerup 2005). Pensamos entonces, que Chachapoya pudo ser un término, como opina Olivier Fabre, asignado por los incas y trasmitido luego a los españoles —entre los cuales figuran algunos cronistas-, quienes no 
discriminaron la propia realidad étnica regional. De otro lado, en la tasa de indios del año 1586, para el servicio de los espańoles que residían en la ciudad de Chachapoyas figuran mitayos de numerosos pueblos de la región, pero ningún mitayo que tuviese como procedencia un pueblo o ayllu denominado Chachapoya (Ruiz Estrada 2011).

Inge Schjellerup ha discutido sobre el grupo humano y la palabra Chachapoya tomando en cuenta las informaciones de varias fuentes, discusión que ayuda a comprender el origen de dicho término y sus connotaciones históricas. La autora precisa que existe inseguridad en los cronistas cuando se refieren a los chachapoya, que dicho nombre solo aparece a partir de la presencia hispana y que es dudoso que ellos se llamaran Chacha. Por ello, puntualiza que es probable que fueron los incas quienes los llamaron así para unificarlos en una sola región que facilitara su administración. Pese a que no existe un sitio, ayllu, pueblo con dicho nombre, Schejellerup afirma con prudencia que Chachapoya "parece haber sido el nombre de uno de los ayllus en los documentos coloniales» (Schjellerup 2005: 59). Es decir, no sabemos al presente cual fue ese ayllu ni se precisa su territorio. Por otro lado, aún en tiempos incaicos cuando las autoridades cusqueñas dividieron en dos sectores los territorios conquistados en Amazonas, permitieron que cada curaca los gobernasen en forma autónoma. Así se desprende de la cita comentada por Martti Parsinen: «Vizcarra incluso asevera que los dos hunocuracas de Chachapoya no estaban subordinados el uno al otro. Por el contrario, ambos gobernaban sus propios huno con iguales derechos» (Parsinen 2003: 283). Es plausible entonces comprender que incluso los incas mantuvieron la tradicional independencia que caracterizaba al sistema de gobierno entre los grupos humanos del actual departamento de Amazonas.

\subsection{Luya y Chillaos}

El reconocimiento de esta región fue aclarándose paulatinamente, pues desde el inicio de la conquista de los antiguos territorios de Amazonas por los españoles, sólo se mencionaba al grupo social Chachapoya. Sin embargo, con frecuencia varios cronistas hicieron referencia a otros pueblos, provincias o territorios comarcanos a los cuales los hispanos conquistaron con el apoyo del grupo Chachapoya. Prácticamente la historia de los luya y chillao, como también de los otros grupos humanos de Amazonas fue silenciada y oscurecida casi por completo. Es probable que los incas y los propios Chachapoya hayan desinformado a los españoles, de ahí que varios cronistas sin conocer la verdadera historia y el territorio de Amazonas, solo difundieron la presencia de los Chachapoya.

Marcos Jiménez de la Espada trae datos sobre los enfrentamientos entre los chillao y los españoles apoyados por indios amigos. Alonso de Alvarado, después de aliarse con los chachapoya de Cochabamba avanzó con etos hacia las tierras norteñas de «Longia», es decir Lonya y «Xunbia» o sea Jumbilla y posteriormente a otra provincia llamada Chillao, cuyos pobladores se habían revelado contra la presencia española y sus aliados, bajo el mando de Guayamil. Finalmente, este rebelde fue apresado y muerto (Jiménez de la Espada 1881: 160, 161, 162, 163)

El año 1558, tan solo a dos décadas y media del ingreso de los españoles al territorio de Amazonas, el arzobispo de Lima Toribio Alfonso de Mogrovejo cita la doctrina de los chillao, cuyo territorio visitó para compulsar la situación del tributo indígena, pues anotó puntualmente la existencia de 320 tributarios nativos que debían de pagar 400 pesos de plata ensayada. Encuentra a los pueblos Chillao que son Yamor (actual Yamón), Zacata, Longuia (actual Lonya), Balchoquistancho, Cumba y Chubazgo. En ningún momento de la visita se hace mención que estos pueblos fuesen Chachapoya. Esto quiere decir que a las dos décadas del ingreso de los españoles a la región de Amazonas ya Chillao , fue considerada como una doctrina, tenía un corregidor, Gerónimo Piña Añasco, un cura, el padre Sebastián Felipe y habían ya dos encomenderos, Isabel de Cespedes y Joan de Fuentes; así como varias estancias en poder de los españoles Baltazar Ortiz, Bartholomé Mendez, Cathalina Jimenez, Luis Vela, Francisco Grandez, Pedro el sastre, a quienes debemos considerar como los primeros pobladores hispanos de esos territorios. No se menciona los nombres de los indígenas, sino solo la del curaca del pueblo de Zacata llamado Alonso Comeca. Este gobernante nativo mantenía aún sus prerrogativas económicas pues tenía doce personas a su servicio 
y muchas vacas, ovejas, yeguas, mulas y cabras (Mogrovejo 1920: 59-60). Como se observa por esta cita, al llegar Mogrovejo a dicha área geográfica, encuentra que esa era la denominación que tenía y no la de Chachapoya, pues de haberse considerado esta denominación, dicho arzobispo los habría reconocido con ese nombre. Vemos también que tal territorio mantenía su nombre, el cual fue respetado por los españoles y conservaron el nombre de Chillao, españolizado como Chillaos.

Las declaraciones realizadas por varios curacas chachapoyanos realizadas el año de 1562, en un expediente sobre las tierras de los huancas - a solo 24 años de la fundación de la ciudad de Chachapoyas-, aclaran los conflictos que existían entre los grupos que poblaron el antiguo territorio hoy denominado Amazonas. Por ejemplo, el curaca Pedro Chuquien de 60 años de edad, afirmaba que ellos salían a combatir con los huancas para defenderse de los «indios contrarios que les daban guerras». El indio principal Pedro Callapa, de más de 60 años de edad manifestaba que ellos tenían guerra con otros comarcanos y él venía a Huancas a pelear con sus indios. El curaca Jesalón dijo que: «antes que los cristianos viniesen a esta tierra los indios Luya nos tenían guerra con estos Guancas hevenia a pelear con ellos muchas veces he que entonces desian viejos he si le hoyo este testigo que esta dicha hoyada e otros pedazos de tierras junto a esta chacra no se sembraba sino antes hera paramo fuele preguntado si después de esto algunaves hoyo decir que esta dicha hoyada se sembraba para los Yngas dixeron las dichas lenguas que el dicho cacique decía que hoyo decir a viejos indios que ya son muertos estaba dicha hoyada hera tierra de los guancas he que no sabemos del caso» (Expediente 3981). Estos datos nos hacen pensar que primero los incas conquistaron a los chachapoyas y que luego, aliados con estos, arremetieron contra los de Luya y otros grupos más. De igual manera, los españoles entraron en alianza con los chachapoyas para derrotar a los grupos de Luya, Chillao y otros de más al Norte. La estrategia del español Alonso de Alvarado fue la misma que empleó Hernán Cortez para la conquista de México, quien se alió con los tlascaltecas y totonacas para derrotar a los aztecas. De otro lado, las declaraciones de los curacas antes mencionados, indican que tenían guerras con indios contrarios por cuyo motivo se habían construido una serie de fortines o pucaras para defenderse de los indios Luya. Tales declaraciones confirman también lo que algunos investigadores habían indicado sobre la existencia de varias agrupaciones humanas en el territorio del hoy departamento de Amazonas, quienes tenían, además, conflictos internos (Espinoza Soriano 1967; Muscutt 1998; von Hagen 2002; Schjellerup 2005; Church 2006: 470; Church y vonHagen 2008; Ruiz Estrada y Ruiz Rubio 2010; Guengerich 2014b, 2015).

Según un documento del año 1592, publicado por el antropólogo alemán Peter Lerche sobre la probanza del linaje de los caciques de Levanto, en el cual testifica Luis Valera quien dijo textualmente que: «Que este gobernador fue quien le dio la provincia a Alvarado y que después le ayudó a conquistar, Luya Chillaos...» (Lerche 1995: 111). Valera se refiere al gobernador de Levanto don Cayo Tupac Rimachi. Esto quiere decir que los castellanos invadieron primero a los chachapoya y enseguida conquistaron a los luya ychillao con ayuda de los de Levanto que comandaba Pedro Cayo Tupac Rimachi. Fue este cacique quien dio la provincia de Chachapoyas a los españoles, según el documento colonial publicado por Lerche. Chachapoyas es considerado en el texto como provincia, también Luya, Chillao y, asimismo, los Chilchos.

El arqueólogo alemán Hans Horkheimer en su cuadro II titulado Comparación de topónimos actuales y antiguos, de su libro El Perú Prehispánico, publicado el año 1950, menciona el nombre actual de la región de Luya cuyo sinónimo antiguo fue nada menos que Chillao (Horkheimer 1950: 153). Horkheimer posiblemente debió tener conocimiento de esta realidad al consultar documentos antiguos que lo llevaron a señalar lo anotado, pues indica que esos sinónimos antiguos corresponden a: «los nombres prehispánicos correspondientes en la trascripción que hacen documentos y relaciones de los siglos XVI y XVII» (Horkheimer 1950: 152).

Es recién a mediados del siglo XVIII, cuando el gobierno español mostró su preocupación por registrar sus posesiones y en razón a ello, ordenó y reiteró la necesidad de que el corregidor de la provincia de Luya procediese a realizar una información puntual de esa provincia. Existe un documento firmado por el virrey Conde Superunda (Expediente 2000) de fecha 28 de setiembre de 1756, en el cual solicita «un puntual mapa y descripción geográfica» que ya se había solicitado 
mediante cédula del 2 de setiembre de 1751, reiterado por otra cédula de fecha 15 de julio de 1755 . Debió ser entonces, como producto de estas cédulas, que recién el año 1762 se dio cumplimiento a dicha preocupación, pese a que dicho territorio ya había sido reconocido como un corregimiento sobre la base de los pueblos de la parte alta y baja de Luya, que allí habitaban, separado de los chachapoya y de las otras agrupaciones humanas. Fue en este año que se dio a conocer la Descripción de la Provincia de Luya y Chillao cuyo autor fue el comisionado Juan Pérez de Astoas. Según esta descripción, se dice que su situación es casi esférica y que por la parte oriental linda con la provincia de Chachapoyas, por la occidental con la gobernación de Jaén de Bracamoros; por el septentrión con la de Cajamarca y por el mediodía con las cabeceras de Lamas, Santa María y montańas que caen al gran Pará y misiones de los padres de la Compañía. Habitaban dicho territorio «aquellos naturales criados y nacidos en ella» y que: «El idioma general assi en los hombres como en las mujeres es el Yndico» (Pérez de Astoas 1996[1762]). Dicho idioma era el quechua que aún persistía en esos tiempos. Ningún documento de la época colonial identifica a los de Luya y Chillao como Chachapoya.

Sus pueblos antiguos se distribuían en dos sectores y el primero ocupaba la parte altoandina de la antigua provincia de Luya que comprendía los territorios de la moderna provincia de Luya, con todos sus distritos y pueblos actuales. Era de temperamento frío. Los centros arqueológicos localizados en dicho territorio se encuentran entre la margen izquierda del río Utcubamba y la margen derecha del río Marañón. Y, actualmente son considerados como los más atractivos, promocionados y visitados de la región de Amazonas. Entre ellos figuran los sitios de Kuélap, Karajía y Revash por ejemplo. De acuerdo a la gran cantidad de asentamientos arqueológicos existentes en dicho territorio debió ser uno de los más poderosos curacazgos antes de la invasión castellana. Hoy configuran los distritos de Luya, Lamud, Paclas, Olto,Trita, Luya Viejo, Coechan, Lonya Chico, Santa Catalina (o Jacapatos), Inguilpata, Colcamar, Tingo, Longuita, Shundur (hoy María), Lopecancha, Santo Tomás y Yeso. En tiempo coloniales formó un corregimiento junto con los Chillaos y uno de sus primeros corregidores fue Francisco Negrillo (Pérez de Astoas 1996[1762]).

El otro sector, según la descripción citada, al que se lo denominaba Chillao, estaba localizado en los territorios de la actual provincia de Utcubamba (Bagua Grande) y parte de Bagua, Yomblón, Cocabamba, Providencia, Collonce, Ocallí, Camporredondo, Lonya Grande, Yamón, Cumba y Jamalca. De acuerdo a las descripciones de tiempos coloniales e incluso republicanos se lo reconoce como un territorio de clima caliente, los cuales proveían tabaco, coca, algodón, cacao y muchas frutas de la tierra.

En resumen, tal documento aclara la denominación que tenía la parte baja, esto es, la de los Chillao de tierra caliente y la parte alta, y la de los Luya de temperamento frío.

El matemático y cosmógrafo español Cosme Bueno redactó un informe publicado en 1764 sobre las provincias del virreinato del Perú, en el cual incluyó una descripción de la provincia de Luyaychillaos y que al igual con las provincias de Cajamarquilla y Collay, además de Chachapoyas integraban en esa época el obispado de Trujillo (Bueno 1951[1764]: 290).

El año 1786 el Diccionario Geográfico Histórico de las Indias Occidentales publicado por Antonio Alcedo, define brevemente a los Chillaos como un pueblo perteneciente a la provincia y corregimiento de ese nombre y lo caracteriza como de temperamento cálido, donde, debido a ese clima, se produce tabaco y almendras. Más exactamente Alcedo precisa que «Chillaos, Pueblo de la provincia y Corregimiento de este nombre en el Perú; es de temperamento calido, produce algún tabaco y almendras.» (Alcedo, 1786: 521). Peter Lerche comentando sobre el líder nativo Chuqui Sota de quien pensamos que procedía del territorio de Luya, advierte que sus enfrentamientos bélicos con los ejércitos de Tupac Yupanqui «fue ignorada a propósito por el levantino Valera, o era por desconocimiento. Probablemente consideraba Valera los grupos étnicos al oeste del río Utcubamba distintos por su macro organización» (Lerche 1995: 55) y añade «Después de la integración de los grupos étnicos chachapoya en el Estado Inca, esta provincia nunca fue fácil de dominarla» (Lerche 1995: 56). 
Un mapa publicado por Inge Schjellerup del año 1793 señala la localización del Partido de Chillaos (Schjellerup 2005: 40). Allí se observa que dicho partido se emplaza entre la margen izquierda del río Utcubamba y la margen derecha del río Marañón y, además, se indica con el número 25 al pueblo de Luya como capital de los chillao.

En el diccionario elaborado por German Stiglich en las primeras décadas del siglo XX se consigna el topónimo Chillao y que este refería a una denominación hecha en tiempos antiguos a los habitantes de una sección de la actual provincia de Luya, que estaban localizados al occidente de la divisoria del Utcubamba Marañón. La propia cita aclara lo afirmado cuando el mencionado diccionario dice que Chillao era la «Designación que se hacía antiguamente de los habitantes que pertenecían a una sección de la hoy provincia de Luya. Era lo que quedaban al W de la divisoria Utucbamba Marañón» (Stiglich 1922: 375).

Alfredo Torero al estudiar las lenguas del nororiente peruano hace mención que los Chillao conformaban una gran entidad étnica o política que se localizaba en los territorios altoandinos entre la cuenca del río Marañón y del Utcubamba. Lo afirma claramente cuando cita que los Chillaos corresponde al «nombre de una gran entidad étnica o política cuyo territorio es situado por otros documentos en las serranías que separan la cuenca del Marañón de la del Utcubamba» (Torero 1993: 461). Esta versión encaja con la ubicación del suelo ocupado en tiempos prehispánicos por los chillao, lo cual se confirma con la mención que hizo el arzobispo de Lima Toribio de Mogrovejo en el año de 1598, de varios pueblos como Yamón y Zacata, a los cuales llegó en una visita pastoral a la región de los Chillao (Mogrovejo 1920).

Otro dato que nos trae Inge Schjellerup cuando comenta al cronista Pedro Sarmiento de Gamboa, es el que durante los enfrentamientos entre Huáscar y Atahualpa para definir el poder del Imperio Inca, fue Huáscar quien contó con el apoyo de 10000 guerreros chillao (Schjellerup 2005: 71). Si esto fue así, entendemos que dicho grupo tenía una importante potencia militar, pues al igual que los chachapoya, fue el otro sector humano que apoyó a Huascar.

El historiador peruano Jorge Zevallos Quiñones considera a los luya y chillao como una nación que poseía territorios muy extensos, localizados entre Lámud y Luya con numerosos pueblos. Zevallos opinaba que la conquista incaica de sus territorios habría quedado trunca. Posteriormente, en tiempos coloniales, los españoles en vista de la extensión que tenía, se vieron obligados a crear un corregimiento, el de Luya y Chillao, similar a los otros corregimientos organizados en la zona (Zevallos Quiñones 1987). Alfredo Narváez, arqueólogo que condujo varias temporadas de trabajo en el complejo arqueológico de Kuélap ha destacado la gran importancia del lugar, por cuya razón opinó en un primer momento que: «Los muros colosales que rodean a la ciudadela enfatizan su carácter militar y estratégico y lo ubican como posible capital política del reino de los Chillaos, uno de los más importantes grupos políticos de esta área, conocido comúnmente como el territorio de la cultura de los Chachapoyas en los Andes nor orientales del Perú» (Narváez 2004: 28). Posteriormente, después de varias temporadas de trabajo, anunció que Kuélap fue la capital política del reino Chachapoya (Narváez 2013: 131).

\subsection{Chilcho}

Fue otra unidad sociopolítica, cuyos pobladores habitaron en el actual valle de los Chilchos al Este del territorio de los chachapoya. Conformó un curacazgo de similar categoría al de los chachapoya. Los restos que actualmente se vienen descubriendo (Lerche 1995; Schjellerup 2005, 2008) corresponden a este grupo humano y se los debe reconocer como tales. Ha sido la arqueóloga Inge Schjellerup, quien registró una buena cantidad de sitios y andenes pertenecientes al territorio de los chilcho, los cuales tenían casas circulares semejantes al de los chachapoya, pero, al mismo tiempo también documentó sitios incaicos con recintos de planta rectangular (Schjellerup et al. 2005). Se comprueba, además, la unidad de los chilcho, cuando Alonso de Alvarado recibió el Título de la Encomienda de este grupo humano junto al de los chachapoya, el año de 1538 por parte de Francisco Pizarro, en mérito a los servicios que venía prestando en la conquista de esos territorios. 
En esa oportunidad Pizarro expresó que le daba: «asimismo el cacique de Chilcho con sus indios e principales e sus subjetos, con tanto que no se entienda en este depósito los caciques ni indios del cacique Zuta, ni los de Caxamalca ni Anaqueniche Puyundo» (Espinoza Soriano 1967: 285). Se aclara también en un testimonio de 1572 cuando se anota que: «Dijeron que de la parcialidad de los Chilchos es cacique principal don Hernando Chilcho. Que solían ser cinco guarangas, e que agora no hay más de los indios contenidos en esta visita. El cual posee el dicho cacicazgo por ejecutoria que tiene de tiempo de diez y seis años a esta parte. Y que en ellos hay seis principales e mas otros tres que son nueve por todos; los cuales dichos prencipalazgos poseen sin que nadie se los pida y que no tienen entre ellos diferencias sobre ellos.» (Espinoza Soriano 1967: 286). De igual manera, en la contienda judicial entre cuatro líderes chachapoyanos figuran como testigos indios viejos como "Antón Amimalo, Pedro Nichán, Alonso Aliochas de la provincia de los Chilchos» (Espinoza Soriano 1967: 293, 309-310). Tenían pues los chilcho sus propios territorios e igualmente sus autoridades, en la misma forma como estaban organizados también los chachapoya. Y los restos arqueológicos que actualmente se vienen registrando en el territorio de los Chilcho fueron las realizaciones culturales que ellos dejaron a la posteridad.

Peter Lerche opina que los Chilcho «controlaban la vertiente oriental andina y las regiones montañosas adyacentes al este de Leimebamba y al noreste de Bolívar entre los ríos de Huabayacu y el actualmente llamado Chilchos» y agrega que: «La etnia de los chilcho era numerosa» (Lerche 1995: 61). Aunque comenta que la alfarería atribuida «a lo Chilcho tiene una vinculación estrecha con el estilo de alfarería cuelapense», así como también que la arquitectura Chilcho no difería de las características básicas de la arquitectura chachapoya (Lerche 1995: 62), se comprende que los Chachapoya no ocupaban los territorios bajo control de los chilcho, por cuya razón los restos arqueológicos hoy existentes son aquellos dejados por los chilcho ancestrales.

Keith Muscutt, hace algunos años opinó que ellos eran virtualmente desconocidos desde el punto de vista histórico y arqueológico, pero llamó la atención sobre el rol que cumplieron en tiempos prehispánicos al afirmar que intermediaron entre los grupos Chachapoya y los de las tierras bajas de la floresta amazónica (Muscutt 1998: 77).

Las investigaciones arqueológicas que se vienen practicando en el valle de los Chilchos informan que incluso la llamada laguna de Los Cóndores, lugar donde se ubicaron impresionantes mausoleos con numerosas momias atribuidas a los chachapoya, forman parte del territorio de los chilcho. Así se afirmó que cuando los incas construyeron caminos en la región uno de estos encaminaba hacia la laguna de Los Cóndores, o lugar de origen de los chilchos, quienes incluso aún en tiempos coloniales conformaban 5000 tributarios (Hagen 2002b: 231).

Se ha enfatizado también que: «El curacazgo de los chilcho y laya parece haber controlado un área que incluía la laguna de Los Cóndores al sur, siguiendo la cordillera Yasgolga, al oeste con una frontera norteña tentativa en río Tingo/Cerro Tolén y que continuaba hacia el noreste hasta el río Mashuyacu, un tributario del río Huayabamba, un área mucho más grande que el actual anexo de Los Chilchos. Los chilcho controlaban, el acceso a varias entradas naturales que conectaban los Andes con las tierras bajas de la Amazonía, una zona sumamente importante para la comunicación y el transporte de los productos de los Andes y de la selva.» (Schjellerup 2008: 114). Es claro entonces, para nosotros, que los chilcho integraron un curacazgo con sus propias autoridades, pueblos y territorios; que este territorio se encontraba entre las cuencas del Huabayacu y los Chilchos, como lo hemos anotado más arriba, en un espacio territorial distinto al de los chachapoya, pero que, desde luego, estuvieron vinculados con estos y participaron de algunos elementos culturales similares. Sin embargo, no sabemos aún el tipo de relaciones políticas que tuvieron con los chachapoya, pero evidentemente fue otro grupo no supeditado a ningún otro curacazgo.

También el historiador peruano Waldemar Espinoza Soriano (2006) nos trae importante información sobre los chilcho en un trabajo que elaboró sobre los mitmas de este grupo, destinados al área de Cajamarca en tiempos incaicos. Espinoza Soriano considera a los chilcho como una etnia constituida por ayllus libres — no sujetos a uno principal— y que tenían un territorio definido al sur de la ciudad de Chachapoyas. En lo cultural, mantuvieron algunas afinidades con 
los otros grupos humanos del antiguo territorio de Amazonas, tal como lo viene demostrando la investigación arqueológica. Sin embargo, no estuvieron sujetos a los chachapoya, sino que tuvieron sus propias autoridades nativas. Incluso cuando se los deportó al sitio de Chetilla, en Cajamarca, ellos siguieron dependiendo de sus propios curacas y en ningún momento se consideraron como Chachapoya. Al producirse la conquista incaica de sus territorios, fue alterada su configuración social y política, pues el gobierno del Cusco los reorganizó de acuerdo a sus propios intereses.

\subsection{Jívaro}

Fueron los pobladores de la propia selva amazónica, al norte de la actual provincia de Bagua, quienes ocuparon - y la ocupan hasta hoy — los territorios de la provincia amazonense de Condorcanqui. De modo general, podemos decir que son grupos numerosos que ocupan los bosques en torno a los ríos Pastaza, Morona, Santiago y Marañón, cuya población se estima en unas 32.000 personas (Larson 1977: 468). Estaba formado por dos grandes unidades humanas, los awajun y los huampis, localizados en territorio peruano. De ellos, actualmente, poco sabemos sobre su trayectoria histórica y cultural, debido a la carencia de investigaciones por lo aislado de su territorio y las difíciles condiciones para su exploración. Sin embargo, existen algunas informaciones de las tribus que conformaban esta gran entidad étnica que por cierto no constituía una sola unidad, sino que estaba integrada por varios grupos étnicos conocidos como los shuar, huambisa, achuar, awajun y maina y «ellos cubren un gran territorio que se extiende desde el Alto Marañón en el Perú hasta el río Zamora en el Ecuador. Su núcleo se localiza sobre el río Santiago desde Macas hasta su punto de unión con el río Marañón encima del pongo de Manseriche» (Myers 2005). Ha sido justamente el arqueólogo Thomas Myers quien distinguió las diferentes tradiciones alfareras de estos grupos, como una prueba de las diferencias culturales existentes entre ellos, pese a su aparente unidad. Creemos que similar situación ocurre para el caso de los denominados Chachapoya, término con el cual se designó a un conjunto de varias unidades étnicas.

Pero la historia de los jívaro corrió paralela al desarrollo de las civilizaciones andinas con las cuales mantuvieron frecuentes interrelaciones, especialmente con las más cercanas como los chillao y los chachapoya. Los territorios que ocuparon estuvieron localizados en las cuencas de los ríos Chinchipe, Imaza, Marañón, Cenepa, Nieva y la gran cuenca del río Santiago. Se sabe que desde tiempos coloniales ellos emprendieron acciones para la defensa de su territorio, y destruyeron varios pueblos fundados por los españoles, quienes insistían en invadir sus territorios. Igualmente, en tiempos contemporáneos, hacia mediados del siglo XVIII, realizaron algunos intentos para desalojar a los colonos posesionados de las áreas de su dominio. Por esa razón atacaron el pueblo de Copallín, cerca de Bagua, obligando a sus habitantes a replegarse por otros lugares. Después de los conflictos del siglo XVI y XVIII, ya en pleno siglo XXI, hemos asistido a nuevos conflictos entre el gobierno peruano y los descendientes de los awajun y wampis. Estos, para defender sus territorios de la intervención externa que pretendía concesionarlos con fines de explotación forestal y del subsuelo, hicieron tomas de la vía que comunica la costa con la selva en señal de protesta. El gobierno peruano para desalojarlos implementó la fuerza con el saldo de numerosos fallecidos entre nativos y policías. Estos últimos acontecimientos vienen a demostrar 500 años de agresión a la nación de los jíbaros.

\subsection{Otros grupos}

Otros menos conocidos todavía, fueron aquellos localizados hacia los límites con Moyabamba, como los grupos Orimona, Cascayunga, Jashalllo, Charasmal. Chedua, Alones, Cholto, Jivito, Cholón y Quisupay. Tenemos conocimiento de ellos según el mapa elaborado sobre su distribución en los territorios de las regiones de Amazonas y Moyobamba (Espinoza Soriano 1967, 2006).

Por otro lado, no podemos dejar de considerar a los grupos de mitimaes que, a partir de la conquista incaica de los territorios de Chachapoyas, estuvieron asentados en ellos. Tenemos así, a los grupos Huancas, Yauyos, Atavillos (Ruiz n.e), Chupachos Cajamarca, Saña y Ferreñafe (Schjellerup 2005: 130-131). 


\section{Consideraciones finales}

Por el resumen expuesto arriba, creemos que no es posible confundir el nombre que tuvo cada unidad étnica, pues al llegar los incas al territorio de Amazonas esa fue la realidad que encontraron, y sobre tal base hicieron cambios administrativos que instrumentaron posteriormente, los cuales se mantuvieron hasta los tiempos coloniales. No hubo pues, un solo grupo humano en el territorio de Amazonas si no varios, los cuales vivían en un sistema reconocido por los cronistas como «behetrías», hoy en día considerado como una federación de curacazgos

Sin embargo, es necesario precisar que aún se carece de investigaciones más profundas que permitan caracterizar las formaciones sociopolíticas que correspondieron a las poblaciones prehispánicas de Amazonas. Desde luego que no habrían sido simples tribus, si observamos solamente el complejo arqueológico de Kuélap, donde aparece una monumental edificación conocida como La Fortaleza, en cuyo interior se aprecian distintos tipos de estructuras que revelan haber tenido también funciones diferentes (Bradley 2005) y, al exterior de ella, varios conjuntos arquitectónicos distribuidos en varios kilómetros a la redonda. El acceso a este complejo es restringido, pues debe lograrse por estrechos callejones que cortan altas plataformas de contención. Es más, se estaba construyendo otro bastión adyacente, denominado hoy la Malca cuya longitud supera a la misma Fortaleza, a lo cual se añade la gran plataforma de la Fila, en el sector más alto del cerro de Kuélap, los cuales, en términos constructivos, son indicadores de una enorme inversión de fuerza humana. $\mathrm{Si}$ el denominado curacazgo de Luya se extendía incluso hasta los territorios de La Jalca, Cheto y el valle de Guayabamba, resultaría que dicha «fortaleza» no estaba en el lindero entre los luya y los chachapoya, sino más bien hacia el centro de los territorios luyanos, punto desde el cual se controlaba ese vasto territorio. Asimismo, Kuélap, que fue erigido en el territorio de los luya y no en el de los chachapoya, conserva restos de tumbas especiales como son los sarcófagos antropomorfos y los mausoleos, destinados a una élite, que obviamente se diferenciaban de otras sepulturas de menor rango, adjudicadas a grupos de poder económico y social inferior. Las tareas constructivas, así como las de trepanar cráneos estuvieron seguramente encargadas a especialistas. En fin, tales construcciones del complejo habrían requerido de un control de la mano de obra para edificarlas, control que emanaba de un poder central ya institucionalizado.

Aparte, desde luego, del grupo social jíbaro y de los otros grupos localizados hacia Moyobamba, cuyos restos son poco conocidos, las restantes unidades étnicas arriba citadas participaron de algunos rasgos culturales comunes, pero tuvieron diferencias en varios aspectos. La arquitectura de las edificaciones circulares fue compartida por todos, pero, al parecer, cada unidad étnica conservó algunos detalles constructivos que los diferenciaban. Tuvieron una alfarería similar en algunos aspectos, pero hubo también diferencias en ciertos estilos. Se sabe actualmente que, por ejemplo, en la parte sur de Amazonas casi no existe la alfarería pintada, la cual es común en la parte norte. Hubieron formas de enterramiento similares, pero algunos se caracterizaron por tener un patrón específico, como los sarcófagos antropomorfos, que se manifiestan únicamente entre los luya y chillao, no entre los chachapoya. Algunas formas de la decoración mural que aparecen en sus recintos adquirieron predominancia en unos y no en otros. Solo citamos estos ejemplos, en vista que todavía queda una enorme cantidad de restos aún no investigados en el territorio de Amazonas, cuyos resultados abrirán nuevas rutas en la comprensión de las peculiaridades de los pueblos para lograr una cabal aproximación a su historia

Sostenemos esta hipótesis mientras avancen las investigaciones in situ, cuyos aportes podrán aclarar el proceso histórico acontecido en Kuélap, en el área de Luya y las otras antiguas unidades sociopolíticas de la región de Amazonas. En todo caso, la presente información no es sino, una motivación para iniciar un deslinde sobre la real composición de los grupos étnicos de Amazonas y, en especial, de los enigmáticos chachapoya. 


\section{FUENTES MANUSCRITAS}

Biblioteca Nacional del Perú (BNP). Lima

1792 Expediente sobre el reconocimiento de los partidos de Sesuya, chillaos y pueblos de Jamalca. Número de Registro C3433

Archivo Regional de Amazonas

1562 Testimonio del pleito seguido por Hernando de Mori con la comunidad de Huancas de la encomienda de Juan Perez sobre unas tierras que comienza en 1562. Número de registro 3981.

1756 José Antonio Manso de Velasco, Conde de Superunda, virrey del Perú ordena una relación de información y la ejecución de un mapa de la descripción geográfica de Luya y Chillaos. Número de Registro 2000 .

Archivo General del Ministerio de Relaciones Exteriores del Perú

1586 Repartimyento General de los indios de mita que ande venir a servir a la plaza de la ciudad de los Chachapoyas y de la horden que e ade tener cerca dello y de la paga que se ade hazer a los indios.

\section{REFERENCIAS}

Alcedo, A.

1789-89 Diccionario Geográfico Histórico de las Indias Occidentales o América, Imprenta Benito Cano, Madrid.

Bauer, B. S., M. Araoz Silva y L. C. Kellet

2013 Los Chancas. Investigaciones arqueológicas en Andahuaylas (Apurimac-Perú), IInstituto Francés de Estudios Andinos, Lima.

Barth, F.

1976 Los grupos étnicos y sus fronteras. La organización social de las diferencias culturales [trad. de Sergio Lugo Rendón], Fondo de Cultura Económica, México D.F.

Bradley, R.

2005 The architecture of Kuelap, tesis de doctorado, Graduate School of Arts and Sciences, Columbia University, New York.

Bueno, C.

[1764] 238-292.

Geografía virreinal del Perú: la Audiencia de Lima en el siglo XVIII, Letras 46,

Church, W.

2006 Chachapoya Indians, en: J. Birx (ed.), Encyclopedia of Anthropology, vol. 2, 469-477, Sage Editors, Thousand Oaks.

Church, W. y A. von Hagen

2008 Chachapoyas: Cultural development at an Andean cloud forest crossroads, en: H. Silverman y W. Isbell (eds.), Handbook of South American Archaeology, 903-926. Springer, New York.

Cieza de León, P.

1962 La crónica del Perú, Colección Austral, Madrid.

Espinoza Soriano, W.

1967 Los Señoríos étnicos de Chachapoyas y la alianza Hispano Chacha, Revista Histórica 30.

2006 La etnia chilcho y su encalve de mitmas en Cajamarca Siglos XV-XI. En Sociales 16. Revista del Instituto de Investigaciones Histórico Sociales. Facultad de Ciencias Sociales. UNMSM. Lima.

Fabre, $O$.

2005 Chaquil, Bulletin hors série du GSBM, Spécial Chachapoyas 2004 \& Soloco 2005, Juin 2006, 71-73

Garcilaso de la Vega, I.

1967 Comentarios reales de los incas, Universidad Nacional Mayor de San Marcos, Lima.

Guengerich, A.

2014a Monte Viudo: Residential architecture and the everyday production of space in a Chachapoya community, tesis de doctorado, Department of Anthropology, University of Chicago, Chicago. 
2014b The architec's signature: The social production of a residential landscape at Monte Viudo, Chachapoyas, Perú, Journal of Anthropological Archaeology 34, 1-16

2015 Settlement organization and architecture in Late Intermediate Period Chachapoyas Northeastern Perú, Latin American Antiquity 26(3), 362-381.

Horkheimer, $\mathrm{H}$.

1950 El Perú prehispánico, Editorial Cultura Antártica, Lima.

von Hagen, A.

2002a Los Chachapoya y la Laguna de los Cóndores, Museo Leymebamba, Leymebamba.

2002b Pueblo de las nubes, en: E. Gonzáles y R. León (eds.), Chachapoyas: el reino perdido, 25-265, AFP Integra, Lima.

Huertas Vallejo, L.

1998 Introducción al estudio de los centros poblados en el Perú durante los siglos XV-XVI, Cantuta. Revista Institucional de la UNE 15, Lima.

Hurtado Ames, C. H.

2013 ¿Huancas o Xauxas? Los Grupos Etnicos Prehispánicos y la invención de la historia en la Sierra Central del Perú, Historia y Región 1(1), 221-242.

Jiménez de la Espada, M.

1881 Relaciones Geográficas de Indias, Biblioteca de Autores Españoles desde la formación del lenguaje hasta nuestros días, Madrid.

Jones, $S$.

2003 The archaeology of ethnicity: Construction identities in the past and present, Taylor \& Francis e-library, New York.

Koschmieder, K.

2012 Jucusbamba. Investigaciones arqueológicas y motivos Chachapoya en el norte de la provincia de Luya, departamento de Amazonas, Lima.

Larson, M. L.

1977 Organización sociopolítica de los Aguaruna (Jíbaro), Revista del Museo Nacional 43, 467-489.

Lerche, $\mathbf{P}$.

1995 Los Chachapoya y los simbolos de su Historia, Servicios Editoriales César Gayoso, Lima.

Mogrovejo, T. A.

1920 Libro de Visitas: Diario de la segunda visita pastoral que hizo de su arquidiócesis al arzobispado de los Reyes, Revista del Archivo Nacional del Perú I-II, 37-78.

Muscutt, K.

1998 Warriors of the clouds: A lost civilization of the upper Amazon of Peru, University of New Mexico Press.

Myers, T. P.

2005 Variación regional y cultural en la cerámica Jívaro, Unay Runa 7, 137-150

Narváez Vargas, A.

2004 Aspectos funcionales de la arquitectura residencial en la Fortaleza de Kuelap, SIAN 9(15), 28.

2013 Kuélap: centro del poder político religioso de los Chachapoyas, en: Los Chachapoyas, Colección Arte y Tesoros del Perú, 87-159, Banco de Crédito del Perú. Lima.

Nystrom, K.

2004 Trauma e identidad entre los Chachapoya, SIAN 9(15), 20-21.

2006 Late Chachapoya population structure prior to Inka conquest, American Journal of Physical Anthropology 131(3), 334-342.

Parssinen, $M$.

2003 Tawantinsuyo. El estado inca y su organización política, Instituto Francés de Estudios Andinos/Fondo Editorial PUCP, Lima.

Pérez de Astoas, F.

1996 Descripción de la provincia de Luya y Chillaos. Kuélap, Boletín Cultural 111, INC-Amazonas.

[1762] 
Rostworowski, M.

2005 Pachacutec. Obras Completas I, Instituto de Estudios Peruanos, Lima.

Ruiz Estrada, A.

2011 La mita de Chachapoyas del año 1586, Investigaciones Sociales, Revista del Instituto de Investigaciones Histórico Sociales 27, 405-420.

n.e Huancas en la historia de Amazonas, Perú.

Ruiz Estrada, A. y R. Ruiz Rubio

2010 La gran historia del pueblo Chillao, Amazonas-Perú, Fondo Editorial de la UNMSM, Lima.

Santillana, J. I.

2002 Chancas e incas: un nuevo examen, El Hombre y los Andes. Homenaje a Franklin Pease G. Y, tomo II, Fondo Editorial PUCP, Lima.

Sarmiento de Gamboa, P.

1988 Historia de los Incas, Miriguano ediciones, Madrid.

Schjellerup, I.

1991 Investigaciones históricas y arqueológicas en la provincia de Chachapoyas, en Perú. Los Incas y el Antiguo Perú 3000 años de Historia. Madrid.

2004 Restos culturales de los Chachapoya y de los Incas: rastros en el paisaje, SIAN 9(15), 8-9.

2005 Incas y españoles en la conquista de los chachapoya, Fondo Editorial PUCP/Instituto Francés de Estudios Andinos, Lima.

2008 Sacando a los caciques de la oscuridad del olvido. Etnías chachapoya y chilcho, Bulletin de l'Institut Francais d 'Etudes Andines 37 (1), 111-122.

Schjellerup, I., V. Quipuscoa, C. Espinoza, V. Peña y M. Kamp Sorensen

2005 Redescubriendo el valle de los Chilchos. Condiciones de vida en la Ceja de Selva, Perú, The National Museum of Denmark, Trujillo.

Stiglich,

1922 Diccionario Geográfico del Perú, Imprenta Torres Aguirre, Lima.

Torero, A.

1993 Lenguas del nororiente peruano: la hoya de Jaén en el siglo XVI, Revista Andina 11(2), 447-472.

Zevallos Quińones, J.

1987 Introducción al estudio etnohistórico de Chachapoyas, Kuélap. Informativo cultural mensual del INC Departamental Amazonas, Boletín 77. Chachapoyas.

Fecha de recepción: 30/05/2016

Fecha de aceptación: 07/02/2017 